\title{
Article
}

\section{Writing as Responsive, Situated Practice: The Case for Rhetoric in Canadian Writing Studies}

\author{
Michael Lukas \\ University of Victoria \\ Tim Personn \\ University of Victoria
}

\begin{abstract}
This article responds to a widely held presumption that ineffective student writing in Canadian classrooms can be resolved through technical solutions on the model of the popular Grammarly app. In contrast, this article suggests that a solution to the problem of writing instruction should focus on how to teach argument through rhetoric as a responsive, situated practice that occurs within different dynamic discourse communities. The article makes this case by recommending a renewed emphasis on the rhetorical concept of kairos, which provides students with an ethical comportment for decision-making in a pluralistic and uncertain world. This article concludes with a call for revitalized interdisciplinary attention to rhetoric in Canadian writing studies and programs.
\end{abstract}

\section{Introduction}

In recent years, writing studies practitioners and scholars in Canada have increasingly made the case for institutional legitimacy, often through a focus on disciplinarity that would "promote greater visibility and agency for writing studies as a discipline in the Canadian academy" (Mueller, Williams, Phelps, \& Cleary-Lemon, 2017, p. 1). This drive to disciplinarity can be seen as an attempt at providing professionally vulnerable practitioners the safeguards of institutional recognition. While this emphasis is understandable, especially in a context where humanities departments are under attack by a neoliberal push to quantify the value of critical reading and writing skills in economic terms, many Canadian scholars have resisted this professionalization of writing as the 
Volume 29, 2019

http://journals.sfu.ca/cjsdw

development of skills to be "audible in the market place," arguing that it serves the demands of business and the neoliberal "imposition of the rule of the cash nexus" (Brooks, 2002, p. 678). We contend that this moment in writing studies at Canadian universities, as practitioners and administrators attempt to establish the goals and desired outcomes for writing instruction, is conditioned by what Kevin Brooks has called a tension between "American pragmatism" and "Canadian philosophical idealism" (Brooks, 2002, p. 673). The Canadian model has traditionally been based in "Canada's old-world roots and the teaching of writing through literary study" (ClaryLemon, 2009, p. 94). As a result, there has been a devaluing of the explicit 'know-how' of rhetoric and argumentation in favour of the implicit acquisition of writing skills through content, especially literary works. In contrast, the American Rhet/Comp tradition has put emphasis on rhetoric; however, in recent years, that approach has too often devalued the particularity and situatedness of all rhetorical inquiry.

Exemplary of the former American pragmatist approach, writing instructor Joseph R. Teller has argued in the Chronicle of Higher Education that a focus on content distracts from the teaching of argumentation, claiming, "the more time a course focuses on 'critical reading' and content, the less time it spends on structure, argument, evidence, logical reasoning, and concise, clear prose" (2016). Teller's article reflects a concern amongst faculty members in the United States that has recently been reiterated in the Canadian context, namely that, as writing professor Doug Hesse points out, colleagues commonly complain to him: "A lot of my students can't even write a decent sentence" (2017). Along similar lines, Canada's premier news magazine Maclean's reported "a flood of anecdotal complaints from professors about what they say is the wretched state of English grammar coming from some of their students" (2010). Teller's response to these perceived deficiencies, however, asks teachers to focus on technical solutions, as if what is desired is a 'human app' that teaches universalizable skills. Seen this way, writing instruction becomes a technical process and the writing instructor an embodied form of the popular Grammarly app. By contrast, we suggest that a solution to the problem of writing instruction should not be located at the sentence level, but on how to teach argument through rhetoric as a responsive, situated practice that occurs within different dynamic discourse communities. We maintain, therefore, that Canadian institutions can indeed draw from American models based in rhetoric, while embracing a contextdependent conversational model consistent with the more traditionally Canadian emphasis on "a social-epistemic approach" that is focused on "a concern for not just the text but for the dialectic of language, discourse community, and material conditions" (Clary-Lemon, 2009, p. 102). To make this 
Volume 29, 2019

http://journals.sfu.ca/cjsdw

case, we draw from both our international educational backgrounds and our classroom practices as writing instructors in Canada and the United States to present a revitalized concept of rhetoric that harkens back to a kairotic conception of rhetorical situation. This kairotic conception of rhetoric emphasizes the ethical implications and responsibilities involved in constructing arguments in a world dominated by powerful institutional rhetorical strategies and conditioned by epistemological uncertainty, where knowledge is socially produced rather than found.

\section{Genre, Particularity, Kairos}

From the perspective of contemporary Canadian writing studies, Katja Thieme (2016) has recently critiqued Teller's assertion that content detracts from writing instruction, arguing that "the gaping hole in Teller's discussion is the concept of genre, and along with it the practice of genre-based pedagogy." Genre, Thieme asserts, is preferable to what she calls Teller's focus on "formulas and language rules," because it allows students to see "in which particular situations" the texts they produce are to be used. We agree with Thieme's focus on particularity, on the ways in which language use is always rooted in the specifics of social interaction, enabled here through the concept of genre. However, our experience as instructors of academic writing and composition at a Canadian university suggests that this focus on particularity can further be reinforced by maintaining a framing of writing instruction through the art of rhetoric, defined as responsive, situated practice. To be sure, the concepts of genre and rhetoric have close ties, as genre theorist Anis S. Bawarshi (2000) indicates when he defines genres as "the rhetorical environments within which we recognize, enact, and consequently reproduce various situations, practices, relations, and identities" (p.336). This concept of a mutual fashioning between generic texts and their rhetorical contexts is also captured by composition scholar Amy Devitt (2000) in her description of "the fuller power of genre" as determined by the idea that "[t]he text, the writer, the context, and the critic, too, as a reader, are shaped by genre" (p. 703).

Indeed, a renewed focus on the relational and responsive aspects of rhetoric can assist in a theoretical impasse of genre theory that has been pointed out by Janet Giltrow (2002), who observes that there are certain "deficiencies" in genre theory's description of situation and context that lead her to conclude that "despite its insistence on situation, genre theory tends to focus on text and neglect surroundings, or underestimate their extent" (p. 202). Indeed, the use of a metaphor such as "rhetorical environment" in major statements of genre theory seems to address precisely this lack of pragmatic entrenchment by specifying the abstract conception of genre as a 
Volume 29, 2019

http://journals.sfu.ca/cjsdw

life world in and by which people and texts are made meaningful. But some knotty philosophical questions remain: How are genres, understood as shaping contexts, constituted themselves? Are they both constitutive of a context and that context itself? In addition to such ontological questions of causal priority, there is the problem that, as David Russell (1997) has noted, the very concept of context in genre theory is prone to the "container" metaphor (p. 506). What this means for a pedagogy of reading and writing is that students may falsely view genre as a rigid form to fill, simply by adhering to abstract rules, and without sufficient attention to how each rhetorical moment exceeds any set of generic rules that can be applied to it. In fact, as Giltrow (2002) has acknowledged in an essay that lays a theoretical foundation for talk of genre under the rubric of 'meta-genre,' any attempts at assembling an exhaustive list of guidelines for the successful production of texts within various institutional contexts face the issue that the various instances of meta-genres "may be too diverse [...] for the phenomenon to count as a category" (p. 202). In her seminal article "Genre as Social Action," based on prior work by communications theorists Karlyn Kohrs Campbell and Kathleen Hall Jamieson, rhetorician Carolyn R. Miller (1984) addresses the pitfalls of this taxonomic drive, arguing that "genre study is valuable not because it might permit the creation of some kind of taxonomy, but because it emphasizes some social and historical aspects of rhetoric that other perspectives do not" (p. 151). In doing so, Miller too recognizes the consequences a lack of pragmatic entrenchment can have for the study of writing as genre. We therefore agree with her critique of any closed, deductive, and taxonomic renderings of genre.

While Miller takes "social exigence" (1984, p. 159) to be a check on the temptation to universalize genre types, we argue that the rhetorical tradition already has a category that functions as a check on typology to maintain openness to the particularities of any rhetorical situation; furthermore, this category can also avoid both ontological questions of causal priority as they relate to the discursive production of contexts and subjects, as well as any false suggestion of the permanence of rhetorical environments. This is the concept of kairos, which, as composition scholar Michael Carter acknowledges, "may be unfamiliar to most contemporary rhetoricians," but "is a concept that is very much worth our attention, primarily because it helps us understand the social foundations of rhetoric" (1988, p. 101). Following Carter, rhetorical scholars such as Bruce McComiskey brought a renewed, though perhaps underappreciated, interest in kairos to rhetoric and writing studies. For McComiskey (2002),

Kairos [...] speaks not of argument from institutional authority, not of an immutable base from which relations to others might be consistently managed; it speaks not a discourse of 
Volume 29, 2019

http://journals.sfu.ca/cjsdw

globalization, as Plato and others did, but a discourse of uncertainty, a discourse of tactics among powerful strategic discourses. Kairotic arguments do not dictate; they respond. (p. 113)

As such, McComiskey argues kairos "remains a potent rhetorical tactic for harnessing the uncertainty of language and the contingency of situational contexts in the interest of democratic political and social ends" (p. 113).

In contrast to the meta-generic aspirations for exhaustive guidelines, "a rhetoric that privileges kairos as a principle of invention does not present a list of rules for finding arguments but rather encourages a kind of ready stance" (Crowley \& Hawhee, 2004, p. 40). Such a kairotic stance suggests a particular notion of space and time the ancient Greeks opposed to chronological time (chronos), the historical or linear time of a clock or a calendar. Instead, kairos is a kind of situational time, like the 'timing' of telling a joke. As such, it involves the awareness of an opportunity to act or speak in a particular situation, a window of time during which action is most advantageous. Kairos is thus an awareness of what is likely needed to persuade an audience given those circumstances. In light of its emphasis on probability, kairos is a tenuous, difficult balancing act that weighs alternatives in the absence of certain proof. Rather than the paralysis of uncertainty, an orientation toward kairos provides audiences with an ethical comportment for decision-making in a pluralistic world where timely action is necessitated despite uncertainty, placing great responsibility on those participating in such discourses to consider myriad conflicting perspectives to develop at best only probable solutions.

In the context of writing instruction, the concept of kairos recognizes the inherent mobility of concepts, in contrast to the conservation of guidelines in an institutional, disciplinary approach. This is evident in our experience with our students, many of whom are institutionally based in the sciences/non-humanities departments and express consistent confusion as to the stylistic recommendation endorsed by writing pedagogues that "academic writing today, even in the sciences and social sciences, makes use of the first person fairly liberally" (Graff \& Birkenstein, 2018, p. 72), as opposed to the traditional expectation that subjectivity has no place in academic prose. As a matter of fact, a 2019 study on writing styles in academic communication found that "highly cited articles" across a range of disciplines in the sciences and humanities "used first-person narration" (Freeling, Doubleday, \& Connell, p. 343). The kairotic focus on particularity and situatedness acknowledges this mobility and tenuousness of disciplinary procedures and the fluidity of audience constitution and participation in producing disciplinary discourses. As such, it 
Volume 29, 2019

http://journals.sfu.ca/cjsdw

acknowledges that audiences do not merely receive knowledge in a discourse community, but are personally implicated in its construction.

It is important to point out that our kairotic conception of rhetoric as responsive, situated practice is notably different from the model of what literary scholar Whitney Sha has recently dismissed as an "all-purpose rhetoric" in the literary magazine The Point. Such a decontextualized conception of rhetoric and argumentation, Sha argues in her critique of certain recent defenses of the humanities, "allows its practitioners to sweep aside knowledge of particulars with their superior ability to debate, persuade and negotiate their way to what they want," thus fulfilling the promise to students "that the humanities lay the foundation for any and all career paths and will make them far more successful than their vocationally oriented peers" (2018). Sha's concern here is to defend the humanities and its particular contents, but in identifying the teaching of rhetoric merely with the ability to "bullshit well" (2018), decoupled from content, she is following in the Platonic tradition of denigrating rhetoric as sophistry, dismissing the situatedness and particularity of rhetoric and argumentation that we emphasize in our teaching of rhetoric as writing instructors. This conception of rhetoric and its application in the classroom is the result of many years of intellectual exchanges between us on the status and importance of rhetoric in contributing to what Tania Smith calls "a healthy civic culture and the development of ethical and creative scholars and leaders" (Smith, 2006). Each of us has brought a unique academic and professional background to these exchanges.

One is affiliated, as translator and interlocutor, with the "Hamburg Group on Argumentation Theory" (Wohlrapp 2014, vi), which has contributed to debates in modern argumentation theory since the early 1980s. The "Hamburg approach" is informed by the internationally renowned Frankfurt School and its "Theory of Communicative Action" (Habermas, 1984), as well as by the Erlangen School and its "Constructive Philosophy of Science" (Lorenzen, 1969), though it ultimately tries to synthesize and supersede both. The other was trained to teach writing in a pedagogically constructivist American Rhet/Comp program emphasizing the social nature of discourse and rhetoric, but has been further informed by experiences as a writing tutor at a Canadian writing centre and a research background in Foucauldian discourse analysis that emphasizes how discourses 'make' truth in particular rhetorical situations. While we have faced constructive disagreements on the status of reason in argument, we found common ground in critiques of the static and logicistic accounts of rhetorical practice by argumentation theorists who adhere to a formalistic tradition of thinking about argument. Specifically, the Hamburg Group was founded on 
Volume 29, 2019

http://journals.sfu.ca/cjsdw

the premise that the 'product approach' to argumentation is too narrow because "argumentation often displays a dynamic in which objections are considered and objections modified" and, furthermore, because "the subjectivity of arguers has to be taken into account" (Wohlrapp 2014, lix). This focus is shared by contemporary discourse analysis in its emphasis on the historicity of discourses and subjects that are continuously formed and reformed through various, but particular and situated, relations of power that are invested in discourses rhetorically. As instructors, we also found significant enough overlap between this orientation on process over product and on arguers' subjective imprinting, on the one hand, and recent innovations in Canadian writing studies, on the other, for us to realize the importance of this shared outlook for a writing pedagogy that attempts to teach writing as responsive, subjectively situated practice.

\section{Kairos in the Classroom}

Based on the above considerations, we have developed a classroom pedagogy that follows a dialectical and conversational model of rhetoric which, in contrast to Teller's decontextualized conception, is necessarily grounded in content and critical reading of texts situated in particular conversations; additionally, in contrast to Sha's mischaracterization of rhetoric as manipulation, we advance a conception of rhetoric that enables participation in dynamic discourse communities.

In the classroom this means taking an approach to rhetoric that asks students, in the words of Doug Hesse, to "analyze the kinds of evidence, structure, and style that will be effective for particular purposes [...], for particular groups of readers [...], and in particular situations" (2017). Rather than, for example, following in the logocentric and logicistic U.S. tradition of hunting down fallacies, which is based on the assumption that certain language games and argumentative schemes are always fallacious, irrespective of what audience and rhetorical situation they are aimed at, we make these conversations and discourse communities explicit. This reflects the dynamic nature of argumentation, which has to stay open to the particularity of any given rhetorical situation. Unlike argumentation theory in its contemporary and traditional, i.e., Aristotelian manifestations, we contend that constructing a veritable 'theory' for identifying instances of fallacious reasoning would be tantamount to restricting the practice of argumentation unnecessarily; however, we also recognize the benefits of realizing some typical possibilities for bias in reasoning.

One way we try to do justice to this dual focus is through the critical analysis of advertisements. For instance, our focus on content allows us to show how rhetoric is operationalized in particular 
Volume 29, 2019

http://journals.sfu.ca/cjsdw

contexts for particular audiences. One effective example we use to initiate students into such critical reading of arguments in advertising is a 2010 American advertisement by the Bushmaster Firearms Company, which depicts its AR-15 rifle accompanied by the tagline, "Consider Your Man Card Reissued" (Ammoland, 2010). In interrogating the advertisement's argument, purpose, and intended audience, students come to understand how advertising participates in particular conversations for particular audiences. In this case, our Canadian classroom students, who are likely not a part of the intended American male audience, come to realize the situated nature of meaning-making with regard to the assumptions shared by members of this particular discourse community. Furthermore, in a particularly pertinent example of kairotic rupture, reading this advertisement alongside the frequent occurrence of mass shootings committed by young white men in North America offers our students insights into the rhetorical underpinnings of an alarming political and cultural trend. This serves an analytical and critical purpose without relying on a generalized theory of fallacy, simply by allowing students to identify the picture of a naturalized masculinity, paired with the nostalgic idea of loss, that the advertisement advances for commercial purposes. But it also fosters a constructive ability for students to see how arguers pitch their arguments in terms of particular audiences and the assumptions that structure them, thus amplifying their own responsiveness to a contemporary kairotic moment in a dynamic and situated way.

This skill is further developed through the op-ed assignment, where we encourage students to participate in particular, situated contexts, and is reinforced by requiring them to respond to arguments that relate to local communities and conversations in order to develop their own argumentative claims within such discourse communities and rhetorical situations, driven by their own curiosity and interest. Doing so gives students a rhetorical purpose, without which, rhetorician and literary critic Wayne C. Booth contends, a student "has not been led to see a question which he considers worth answering, or an audience that could possibly care one way or the other" (1963, p. 142). Thus, in teaching the op-ed, we follow Booth's idea that "the supreme purpose of rhetoric is not to talk someone else into a pre-conceived view" (1974, p. 147). Rather, as Booth notes, the purpose of rhetoric "must be to engage in mutual enquiry or exploration to make each other in symbolic interchange" (1974, p. 147). This co-making in symbolic exchange, consistent with the Burkean model of argument as always situated in conversation and discourse communities (Burke, 1941), has implications for our practice of how to teach writing as argument, namely by inviting students into a dynamic process of inquiry and discovery. 
Volume 29, 2019

http://journals.sfu.ca/cjsdw

Emblematic of this orientation is the "Burkean parlor," Kenneth Burke's well-anthologized description of entering academic discourse as akin to entering a conversation at a party. And while we do teach this familiar analogy to emphasize discourse as an interminable social process, it is perhaps Burke's comments a few pages earlier in The Philosophy of Literary Form that are particularly relevant for emphasizing the process of responsive discourse over its product. Burke reminds us that

Every document bequeathed us by history must be treated as a strategy for encompassing a situation. Thus, when considering some document like the American Constitution, we shall be automatically warned not to consider it in isolation, but as the answer or rejoinder to assertions current in the situation in which it arose. (1941, p. 109)

Thus, this Burkean approach also casts a new light on the distinction in writing studies between a process and a product orientation. To be sure, our kairotic approach to the op-ed is certainly in line with the contemporary emphasis on 'writing as process', which leads a critic like Teller to be suspicious that this might make argumentation unteachable. However, as previously noted, we cannot agree with his insistence that the teaching of "rhetorical modes" should not be muddied by "tackling complex issues" (Teller, 2016). In fact, our model shows that it is possible for the writing classroom to be both process- and product-oriented at the same time, as we draw from students' everyday habits of mind and experiences, which often involve the kind of rhetorical moves that academics make. Thinking through complex issues provides the opportunity to make these moves and modes explicit. To be sure, this still leads to the creation of end products, but the emphasis remains on participation in discourse communities, as we acknowledge that any 'product' is situated in an ongoing process of argumentation that is public and responsive. The op-ed, which tends to invite response and encourages students to participate in an ongoing dialogue and submit claims responsive to localized conversations, is a particularly appropriate way of teaching writing as argument. Indeed, such framing of argument as participation in discourse communities promotes an ethical comportment where responsiveness and attunedness to interlocutors replaces an orientation toward a decontextualized, marketable skill set for 'winning' arguments. This further undermines the framing of argument as a binary-focused, zero-sum game, instead focusing students on constructing probable answers for which there are no singularly "right" or "wrong" solutions. 
Volume 29, 2019

http://journals.sfu.ca/cjsdw

\section{Conclusion}

In Plato's dialogue Gorgias, the eponymous sophist famously confirms Socrates's tongue-in cheek characterization of rhetoric as of "superhuman importance" (Plato, 1961, 456a). While some would defend rhetoric on this basis as a meta-discipline for all the disciplines, we recognize the danger that doing so might lead to a conception of rhetoric as a superior form of manipulation that is not attuned to an ethics of response or the particular situatedness of knowledge claims. Still, we maintain that the study of rhetoric in the writing classroom is well suited for teaching what it takes to be persuasive in a variety of discourse communities. Indeed, Gorgias' response regarding his brother's trouble as a doctor convincing a patient to take medicine is reflective of such comportment (456b). In this paper, we have argued that this explicit development of our students' persuasive faculties teaches them better writing, but also an ethics of response. In short, as we remind our students through a screening of a key exchange between Uncle Ben and Peter Parker in Sam Raimi's Spider-Man (2002), "With great power comes great responsibility."

Two suggestions follow from our argument, regarding the composition of writing programs and the development of curricula in line with our conception.

Since, as Clary-Lemon (2009) observes, "disciplinarity [...] was a late arrival in Canada" compared to the United States (p. 99), there is an opportunity to use this lack of dedication to disciplinarity as an advantage for Canadian writing programs. In particular, the fact that Canada already has many instructors with diverse interdisciplinary backgrounds should be recognized as a unique strength. In their 2018 study on the benefits and challenges of WIL (Writing-Intensive Learning) pedagogy, Marshall and Walsh Marr describe the "ideal WI instructor" as one who resists a strict separation between content and language and instead represents "an idealization of teaching and learning through writing at the university" by taking "a lenient view on dealing with student errors, preferring to overlook them in favour of focusing on content" (2018, p. 40). Marshall and Walsh Marr conclude that universities "should aspire to hire" such a "rounded WI instructor" but lament that he or she "is the exception rather than the norm" (2018, p. 40). However, it seems to us that the large presence of interdisciplinary programs in Canada can actually provide such 'rounded' candidates, if writing instruction is not restricted to instructors and tutors with specialized degrees in Rhetoric and Composition. Indeed, we have observed the feasibility of such a focus in our own institutional context by working closely with the University of Victoria's Centre for Academic Communication (CAC), whose writing tutors come from a variety of disciplinary 
Volume 29, 2019

http://journals.sfu.ca/cjsdw

backgrounds. Such interdisciplinary scholars may even present an opportunity for engagements across the disciplines in courses in advanced rhetoric and argumentation that engage topics through a multiplicity of disciplinary lenses. At some American institutions, such as the University of Montana, these kinds of courses were intended to allow students to gain an understanding of how different discourse communities frame topics of conversation and to participate in these conversations by drawing upon particular means of persuasion in light of discursive conventions and documentation systems appropriate to specific writing tasks. In a "health and society"-themed advanced Rhetoric and Composition course, for instance, students examined the rhetoric around disease in a variety of historical contexts, from discourses around leper colonies in the Middle Ages, to scapegoating during the plague, to the moral framing of the AIDS crisis in the 1980s, and contemporary discourses around vaccination. In consideration of their own diverse backgrounds, students learned to unpack the tensions in these discourses through a variety of disciplinary tools they brought to the table, from psychology, to sociology, and medicine. As we have indicated in this paper, instructors who can negotiate these various overlapping disciplinary threads are particularly well suited to such rhetorical inquiry.

While composition scholar Louise Wetherbee Phelps sees a future for Canadian writing instruction by invoking the Quaker adage, "Proceed as way opens" (2014, p. 18), we contend that one such way to proceed, which resists calls for professionalization in a neoliberal mode, is a revitalized interdisciplinary attention to rhetoric in Canadian writing studies and programs. This approach stands in opposition to the teaching of an all-purpose technical rhetoric without an ethics of response. Indeed, consistent with the traditional Canadian dedication to social-epistemic values, we argue that Canadian scholars are well positioned to promote and implement this conception of writing as a responsive and situated practice across the disciplines, especially given the interdisciplinary orientation of the Canadian academy at large.

\section{References}

Bawarshi, A. S. (2000). The genre function. College English, 62, 335-360.

Booth, W.C. (1974). Modern dogma and the rhetoric of assent. Chicago, IL: University of Chicago Press.

Booth, W.C. (1963). The rhetorical stance. College Composition and Communication, 14 (3), 139-145. 
Volume 29, 2019

http://journals.sfu.ca/cjsdw

Brooks, K. (2002). National culture and the first-year English curriculum: A historical study of "Composition" in Canadian universities. American Review of Canadian Studies, 32(4), 673-694. https://doi.org/10.1080/02722010209481679

Burke, K. (1941). The philosophy of literary form: Studies in symbolic action. Baton Rouge, LA: Louisiana State University Press.

Carter, M. (1988). Stasis and kairos: principles of social construction in classical rhetoric. Rhetoric Review, 7 (1), 97-112. Retrieved fromhttp://www.jstor.org/stable/465537

Clary-Lemon, J. (2009). Shifting tradition: Writing research in Canada. American Review of Canadian Studies, 39(2), 94-111. https://doi.org/10.1080/02722010902848128

Crowley, S. \& Hawhee, D. (2004). Ancient rhetorics for contemporary students (3 ${ }^{\text {rd }}$ ed.). New York, NY: Pearson Publishing.

Devitt, A. (2000). Integrating rhetorical and literary theories of genre. College English, 62, 696-718. Giltrow, J. (2002). Meta-Genre. In R. Coe, L. Lingard, \& Tatiana Teslenko (Eds.). The rhetoric and ideology of genre: Strategies for stability and change. Creskill, NJ: Hampton Press, 187-205.

Freeling, B., Doubleday, Z. A., \& Connell, S. D. (2019). How can we boost the impact of publications? Try better writing. PNAS, 116(2), 341-343.

Graff, G. \& Berkenstein, C. (2018). They say/I say (4th ed.). New York, NY: Norton. Habermas, J. (1984). The theory of communicative action. Cambridge, MA: MIT Press.

Hesse, D. (2017, January 3). We know what works in teaching composition. Chronicle of Higher Education. Retrieved from https://www.chronicle.com/article/We-Know-What-Works-inTeaching/238792

Lauer, J.M. (1982). Writing as inquiry: Some questions for teachers. College Composition and Communication, 33(1), 89-93. https://doi.org/10.2307/357847

Lorenzen, P. (1969). Normative logic and ethics. Mannheim, Germany: Bibliographisches Institut. MacLean's (2010, February 1). University students can't spell. Retrieved from https://www.macleans.ca/education/uniandcollege/university-students-cantspell/

Marshall, S. \& Walsh Marr, J. (2018). Teaching multilingual learners in Canadian writing-intensive classrooms: Pedagogy, binaries, and conflicting identities. Journal of Second Language Writing, 40, 32-43.https://doi.org/10.1016/j.jslw.2018.01.002

McComiskey, B. (2002) Gorgias and the New Sophistic Rhetoric. Carbondale, IL: Southern Illinois University Press. 
Volume 29, 2019

http://journals.sfu.ca/cjsdw

Miller, C.R. (1984). Genre as social action. Quarterly Journal of Speech, 70 (2), 151-167. https://doi.org/10.1080/00335638409383686.

Mueller, D., Williams, A., Phelps, L.W., \& Clary-Lemon, J. (2017). Cross-border networks in writing studies. Anderson, SC: Parlor Press.

Phelps, L. W. (2012). The historical formation of academic identities: Rhetoric and composition, discourse and writing. Canadian Journal for Studies in Discourse and Writing/Rédactologie, 25(1), https://doi.org/10.31468/cjsdwr.37

Plato. (1961). Gorgias. In E. Hamilton \& H. Cairns (Eds.), Plato: The collected dialogues (229-307). Princeton, NJ: Princeton Univ. Press.

Proof of your manhood - the man card from Bushmaster (2010). Ammoland. Retrieved from https://www.ammoland.com/2010/05/bushmaster-man-card/\#axzz5fS5fo35h

Raimi, S. (Director). (2002). Spider-Man. United States: Sony Pictures.

Russel, D. (1997). Rethinking genre in school and society. Written Communication, 14(4), 504-554.

Sha, W. (2018). Subjectivity and its discontents. The Point. Retrieved from https://thepointmag.com/2018/criticism/subjectivity-and-its-discontents

Smith, T. (2006). Recent trends in undergraduate writing courses and programs in Canadian universities.. In R. Graves \& H. Graves (Eds). Writing centres, writing seminars, writing culture: Writing instruction in Anglo-Canadian universities (319-370). Winnipeg, MB: Inkshed Press.

Teller, J.R. (2016, October 3). Are we teaching composition all wrong? Chronicle of Higher Education. Retrieved from https://www.chronicle.com/article/Are- We-Teaching-Composition/237969

Thieme, K. (2016, October 10). What do you teach when you teach writing? Medium. Retrieved from https://medium.com/@KatjaT/what-do-you-teach-when-you-teach-writing-e559e7c6643d

Wohlrapp, H. R. (2014). The concept of argument: A philosophical foundation. Dordrecht, Germany: Springer. 